\title{
Appropriate Antibiotic Use for Community-Acquired Pneumonia in Inpatient Settings and Its Impact on 30-days Readmission and Mortality Rate
}

\author{
Rafida Sofi Kamila ${ }^{1}$, Maftuchah Rochmanti ${ }^{2 *}$, Arief Bakhtiar $^{3}$ \\ ${ }^{1}$ Student, Faculty of Medicine, Universitas Airlangga, Surabaya - Indonesia 60131, ${ }^{2}$ Lecturer, Department of \\ Pharmacology and Therapeutics, Faculty of Medicine, Universitas Airlangga, Surabaya 60131 - Indonesia, \\ ${ }^{3}$ Lecturer, Department of Pulmonology and Respiratory Medicine, Faculty of Medicine, Universitas Airlangga, \\ Surabaya 60131 - Indonesia
}

\begin{abstract}
Background: Community-Acquired Pneumonia (CAP) is a lower respiratory tract infection with bacteria as the most frequent causative agent. Therapy for pneumonia includes appropriate antibiotic usage. Inappropriate antibiotic use supposedly increase 30-days readmission and mortality rate.

Objective: To evaluate the antibiotic use and the impact of appropriate antibiotic use on the 30-days readmission and mortality of CAP patients in inpatient non-ICU settings.

Method: A cross-sectional, analytic study was conducted. We collected data from Universitas Airlangga hospital's medical record to obtain the details of antibiotic usage. Result were evaluated using the Gyssens algorithm. A chi-square test was used to identify the impact of appropriate antibiotic use on the 30-days readmission and mortality.

Result: A total of 90 patients with CAP fulfilled the inclusion criteria. One gram of ceftriaxone IV was the most prescribed antibiotic for therapy of CAP. The amount of appropriate antibiotic use is $85.6 \%$. Five patients $(5.6 \%)$ went through the 30-days readmission. There was no death reported. The statistical test between antibiotic use and 30-days readmission obtained $p$ value $=0.894(p>0.05)$.
\end{abstract}

Conclusion: There was no significant impact of appropriate antibiotic use on the 30-days readmission rate and the mortality rate could not be assessed.

Keywords: 30-days readmission, antibiotic use, community-acquired pneumonia, Gyssens algorithm, mortality

\section{Introduction}

Antibiotic resistance can occur due to inappropriate antibiotic use. This unabating phenomenon increasingly becomes a problem in public health issues. Antibiotic resistance will rapidly increase along with inappropriate antibiotic use ${ }^{1-3}$. As methicillin was widely used in the 1960s, Staphylococcus aureus soon becomes resistant to the drug, treatment decision for MRSA infection can be challenging due to a change in its Penicillin Binding Protein (PBP) so that it is resistant to beta-lactam class antibiotics $^{4-6}$. WHO stated that in 2013, at least 700.000 people died due to antimicrobial resistance to bacterial infection, malaria, HIV/AIDS, and tuberculosis. WHO also predicted that there will be approximately 10 million death due to antimicrobial resistance in $2050^{7}$. Appropriate antibiotic usage is substantial to the success of therapy. Inappropriate Empirical Therapy (IET) is said to be associated with a potentially worse outcome such as higher 30-day readmission rates and mortality rate $^{8}$.

Lower respiratory tract infections, such as CAP, are the most common infection cause of death in the world and are the third cause of global death in $2008^{9}$. The mortality rate among CAP patients in non-ICU general 
ward setting is reported to be around $2 \%$. This rate increases in the ICU setting, $>65$ years, male, and patient with co-morbid diseases ${ }^{10}$. This study was conducted to identify the appropriate antibiotic use in CAP patients and also to evaluate the impact of appropriate antibiotic use on the 30-days readmission and mortality of CAP patients.

\section{Methods}

This was a cross-sectional study that included all CAP patients (ICD code J18.9) admitted in inpatient non-ICU settings and were diagnosed with pneumonia in their first assessment examination. Patients were over 18 years old and hospitalized in the general ward of Universitas Airlangga hospital, Surabaya, East Java, from 1 January 2018 to 31 December 2018. We observed the antibiotic use in CAP patients through their medical records and collected data on patients' characteristics, i.e., sex, age, admission date, and length of stay. We also collected data on patients' antibiotic prescriptions, i.e., type of antibiotic, duration of therapy, dosage, route, timing, and interval time of prescription. Later we also observed the patients' outcomes; 30-days readmission and mortality. The independent variable in this study was the antibiotic usage in CAP patients and the dependent variables will be 30 -days readmission and mortality. We excluded those with incomplete medical records, patients with other infections, and patients who had been discharged against medical advice (DAMA). Total sampling was used in this study. Antibiotic usage was evaluated using the Gyssens algorithm and on the clinical practice guideline of the ATS/IDSA 2019 as well as the local guideline from Perhimpunan Dokter Paru Indonesia (PDPI) 2014 11,12. The Gyssens algorithm is a qualitative measurement to assess antibiotic usage and has been widely used in worldwide studies. The Gyssens algorithm will show the rationality of antibiotic usage based on grouping of $0-\mathrm{VI}$ categories $^{2,13}$. A chi-square test was used to identify the impact of appropriate antibiotic use on the 30-days readmission and mortality.

\section{Result}

We collected 90 patients' medical records who fulfil the inclusion and exclusion criteria of the study. Patients characteristic is shown in Table 1. The majority of the patient was female $(57.8 \%)$, aged 45-64 years old $(50 \%)$, and with the length of stay for 4 days $(37.8 \%)$. Ceftriaxone $(56.7 \%)$ was the most prescribed antibiotic for CAP, followed by levofloxacin $(28.9 \%)$, ceftazidime $(7.8 \%)$, meropenem $(3.3 \%)$, cefixime $(1.1 \%)$, cefotaxime (1.1\%), and azithromycin (1.1\%). Evaluation of antibiotic usage using the Gyssens algorithm will be expressed as 'appropriate' and 'inappropriate' and is shown in Table 2. Antibiotic use in 77 prescriptions were considered as appropriate $(85.6 \%)$ while in 13 prescriptions were inappropriate (14.4\%), according to Gyssens algorithm. The most common type of error was category IIIB (shortened duration) (11.1\%). One prescription (1.1\%) was classified as category IVA (alternating agent is more effective) and two prescriptions (2.2\%) were classified as category VI (incomplete medical record), one of them showed no data of the interval time and the other contained no data regarding the timing of the prescription. It is reported that 5 of 90 patients $(5.6 \%)$ underwent the 30-days readmission (Table 3.), in which 3 of them were more than 65 years old and 4 of 5 them had co-morbid diseases (Table 4.). All five patients who underwent the 30-days readmission had already been given the appropriate antibiotic prescriptions in their initial treatment $(p=0.894)$ (Table 5). No mortality is reported in this study (Table 6.) 
Table 1. Characteristics of patient with CAP in 2018

\begin{tabular}{|c|c|}
\hline Characteristics & Total (n) \\
\hline \multicolumn{2}{|l|}{ Gender } \\
\hline Male & 38 \\
\hline Female & 52 \\
\hline \multicolumn{2}{|l|}{ Age (years) } \\
\hline $18-24$ & 2 \\
\hline $25-44$ & 7 \\
\hline $45-64$ & 45 \\
\hline$>65$ & 36 \\
\hline \multicolumn{2}{|c|}{ Length of Stay (day) } \\
\hline 2 & 4 \\
\hline 3 & 28 \\
\hline 4 & 34 \\
\hline 5 & 12 \\
\hline 6 & 5 \\
\hline 7 & 2 \\
\hline 8 & 3 \\
\hline 9 & 2 \\
\hline \multicolumn{2}{|l|}{ Antibiotics } \\
\hline Ceftriaxone & 51 \\
\hline Ceftazidime & 7 \\
\hline Meropenem & 3 \\
\hline Cefixime & 1 \\
\hline Cefotaxime & 1 \\
\hline Levofloxacin & 26 \\
\hline Azithromycin & 1 \\
\hline \multicolumn{2}{|c|}{ Duration of Therapy (day) } \\
\hline 2 & 1 \\
\hline 3 & 8 \\
\hline 4 & 2 \\
\hline 5 & 3 \\
\hline 6 & 4 \\
\hline 7 & 10 \\
\hline 8 & 39 \\
\hline 9 & 14 \\
\hline 10 & 5 \\
\hline 11 & 3 \\
\hline 12 & 1 \\
\hline \multicolumn{2}{|c|}{ 30-Days Readmission } \\
\hline Yes & 5 \\
\hline No & 85 \\
\hline \multicolumn{2}{|l|}{ Mortality } \\
\hline Yes & 0 \\
\hline No & 90 \\
\hline
\end{tabular}


Table 2. Quality of antibiotic use expressed in Gyssens Category

\begin{tabular}{|c|c|}
\hline Gyssens Category & Total (n) \\
\hline 0 & 77 \\
\hline Appropriate & 77 \\
\hline I & 0 \\
\hline II A & 0 \\
\hline II B & 0 \\
\hline II C & 0 \\
\hline III A & 0 \\
\hline III B & 10 \\
\hline IV A & 1 \\
\hline IV B & 0 \\
\hline IV C & 0 \\
\hline IV D & 0 \\
\hline V & 0 \\
\hline VI & 2 \\
\hline Inappropriate & 13 \\
\hline Total & 90 \\
\hline
\end{tabular}

Note: 0: Appropriate; I: Inappropriate timing; IIA: Inappropriate dose; IIB: Inappropriate interval, IIC: Inappropriate route; IIIA: Prolonged duration; IIIB: Shortened duration; IVA: More effective alternating agent; IVB: Less toxic alternative agent; IVC: Less cost alternative agent; IVD: Narrower spectrum alternative agent; V: Inappropriate indication; VI: Incomplete medical record

Table 3. 30-days readmission in CAP patients

\begin{tabular}{|c|c|}
\hline 30-days readmission & Total (n) \\
\hline No & 85 \\
\hline Yes & 5 \\
\hline Total & 90 \\
\hline
\end{tabular}

Table 4. Risk Factors in Patients undergo 30-days readmission

\begin{tabular}{|c|c|c|}
\hline \multirow{2}{*}{} & \multicolumn{2}{|c|}{ Risk Factors } \\
\cline { 2 - 3 } & Age & Co-morbid disease \\
\hline Patient 1 & $>65$ & Malignant Neoplasm, Bronchus or Lung \\
\hline Patient 2 & $>65$ & Mediastinum tumor \\
\hline Patient 3 & $>65$ & COPD \\
\hline Patient 4 & $45-64$ & Heart Failure \\
\hline Patient 5 & $45-64$ & \multicolumn{2}{|c|}{} \\
\hline
\end{tabular}


Table 5. Crosstabulation between 30-days readmission and Gyssens category

\begin{tabular}{|c|c|c|c|c|}
\hline \multirow{2}{*}{ 30-days readmission } & \multicolumn{2}{|c|}{ Gyssens Category } & \multirow{2}{*}{ Total } & \multirow{2}{*}{ p value } \\
\cline { 2 - 4 } & (Gyssens 0) & (Gyssens I-VI) & & \\
\hline No & 72 & 13 & \multirow{2}{*}{0.894} \\
\hline Yes & 5 & 0 & 5 & \\
\hline Total & 77 & 13 & 90 & \\
\hline
\end{tabular}

Table 6. Mortality in CAP patients

\begin{tabular}{|c|c|}
\hline Mortality & Total (n) \\
\hline No & 90 \\
\hline Yes & 0 \\
\hline Total & 90 \\
\hline
\end{tabular}

\section{Discussion}

\section{Types of Antibiotic}

According to the 2019 ATS/IDSA Guideline for adults with CAP, two regimens are strongly recommended for CAP therapy in an inpatient setting; monotherapy of levofloxacin and combination therapy of beta-lactam and macrolide. Alternative for adults with both macrolide and fluoroquinolone contraindications is the combination therapy of beta-lactam and doxycycline 11 .

Monotherapy of levofloxacin was prescribed in 26 patients $(29.3 \%)$. A systemic review from 16 randomized control study reported that monotherapy of levofloxacin significantly caused less clinical failure, withdrawal, and diarrhea compared to the combination therapy of betalactam and macrolide ${ }^{14}$.

Monotherapy of beta-lactam was prescribed in 63 patients $(70 \%)$ and is the most prescribed antibiotic regimen for adults with CAP. Aside from combination therapy, monotherapy of beta-lactam can also be considered as an alternative for inpatients with nonsevere CAP ${ }^{11}$. A randomized controlled trial in 580 patients reported that monotherapy of beta-lactam failed to show noninferiority to combination therapy of betalactam and macrolide in moderately severe communityacquired pneumonia ${ }^{15}$. Another randomized controlled trial study also reported that there is no difference in mortality, complication, and length of stay between monotherapy and combination therapy in CAP patients 16 .

One patient $(1.1 \%)$ was prescribed with macrolide azithromycin as their empirical CAP therapy. Macrolide monotherapy is an antibiotic option for adults with CAP in outpatient settings, and is not recommended in inpatient settings ${ }^{11}$. Macrolide works effective intracellularly and covers pathogens such as Grampositive bacteria, Legionella, Mycoplasma pneumoniae, and Chlamydia pneumoniae ${ }^{17}$. However, macrolide monotherapy should be given based on the resistance level and that is based on studies of macrolide failures in patients with macrolide-resistant S. pneumoniae ${ }^{18,19}$. The rate of macrolide resistance among Streptococcus pneumoniae isolates in the United States is reported for $>30 \%$, a high level of resistance ${ }^{20}$.

\section{Duration of Therapy}

It is reported that 79 out of 90 prescriptions (87.8\%) were given for no less than 5 days, while 11 prescriptions $(12.2 \%)$ were given for $<5$ days. According to the guideline by ATS/IDSA 2019, the duration of therapy should be guided by clinical stability (resolution of vital sign abnormalities), ability to eat, and normal mentation. Antibiotics should be given until clinical improvement 
is achieved and is strongly recommended to be given for no less than a total of 5 days. Recent data supported that administering antibiotics for less than 5 days is barely sufficient. As most patients will achieve clinical stability in the first 48-72 hours of therapy, the total duration of therapy for 5 days will be sufficient for most patients and 7 days for CAP due to suspected or proven MRSA or Pseudomonas aeruginosa ${ }^{11,21}$.

\section{Appropriate Antibiotic Use}

There were 77 prescriptions (85.6\%) classified as Gyssens 0, which means that the antibiotic use is appropriate. The result also shows that 10 prescriptions (11.1\%) were classified as Gyssens IIIB, which means that the total duration of antibiotic therapy is too short (less than 5 days). Gyssens IIIB is the most common error found in this study. Another type of error is Gyssens IVA, which is found in 1 prescription (1.1\%). Gyssens IVA implies that the antibiotic prescription is not appropriate because other antibiotics are more effective. One prescription in this category received azithromycin monotherapy. Azithromycin, which is a macrolide class of antibiotics, should be used together with beta-lactam antibiotics in empirical therapy for CAP in non-ICU inpatients ${ }^{11,12}$. The combination of beta-lactam and macrolide antibiotic therapy is said to provide better results than monotherapy which associated with a reduction in mortality and / or a shorter length of stay compared to the monotherapy with beta-lactam ${ }^{22}$.

The use of antibiotics as empirical therapy for CAP in this study can be concluded to have a rate of $85.6 \%$ of appropriate antibiotic use and $14.4 \%$ in other categories (Gyssens I-VI).

\section{0-days Readmission}

Five patients $(5.6 \%)$ underwent readmission with the same diagnosis within 30 days after the patient was discharged. Early hospital readmission is a common and costly occurrence in elderly and high-risk patients. To improve the quality of care and to reduce unnecessary health expense, policymakers have made reducing 30days readmission as a priority ${ }^{23}$. The incidence of 30 days readmission is often found in patients with $\mathrm{CAP}^{24}$. Zillberg et al stated that the 30-days readmission rate would increase if patients received inappropriate empirical therapy ${ }^{8}$. However, all five patients who underwent the 30-days readmission in this study had received appropriate therapy (Gyssens 0 ) on their initial CAP treatment. The statistical test between the 30-days readmission and the appropriate antibiotic use with chisquare test method obtained $p$-value $=0.894(\mathrm{p}>0.05)$, suggesting that the incidence of 30-days readmission is not influenced by the appropriate antibiotic use and it can be concluded that the appropriate antibiotic use in this study has no significant impact on the 30-days readmission.

Undergoing the 30-days readmission while receiving appropriate therapy in the patients' initial infection can occur due to some considerations. Factors such as age, immunodeficiency, malignancy, heart failure, and chronic conditions can increase the proportion of pneumonia cases that fail to have complete resolution. In other words, readmission for pneumonia may occur due to unavoidable causes. Patients with COPD, heart failure, diabetes, and malignancy will increase the proportion of readmission for pneumonia cases ${ }^{25}$

In this study, 3 patients who underwent readmission were $>65$ years old. Old age is related to a decrease in the general condition of the functional organ so individuals are more at risk of developing pneumonia ${ }^{26}$. Meanwhile, 4 patients had medical conditions other than CAP itself, such as malignancy, COPD, and heart failure. Those are known factors that cannot be avoided in readmission of CAP cases ${ }^{25}$.

\section{Mortality}

No mortality was found in this study. According to the guideline by PDPI in 2014, the mortality rate of CAP in inpatient settings is $5-20 \%$ and it will greatly increase in intensive care unit by more than $50 \%$. However, it is also stated that the prognosis for CAP is generally good depending on several factors such as patient factors, causative bacteria, and the use of appropriate antibiotics ${ }^{12}$. We could not assess the impact of the appropriate use of antibiotics on mortality rate as there is zero mortality in both appropriate and inappropriate antibiotic use in this study.

\section{Conclusion}

Appropriate antibiotic use in adults with CAP in inpatient non-ICU settings of Universitas Airlangga 
Hospital is $85.6 \%$. The most common error in antibiotic usage is shortened duration (Gyssens IVA). The 30days readmission rate is $5.6 \%$ and the mortality rate is zero. There was no significant impact of appropriate antibiotic use on the 30-days readmission and the impact of appropriate antibiotic use on mortality rate could not be assessed as there was no death in this study.

Ethical Clearance: This original research study had been approved by the Universitas Airlangga hospital Surabaya ethical committee in health research (3594/ UN3.9.1/PPd/2019).

Conflict of Interest: The authors declare that they have no conflict of interest.

Source of Funding: Self funding.

\section{References}

1. Kementrian Kesehatan RI. Modul Penggunaan Obat Rasional. 2011;3-12.

2. Rachmah EA, Rochmanti M, Puspitasari D. Impact of an antimicrobial resistance control program: preand post-training antibiotic use in children with typhoid fever. Paediatrica Indonesiana. 2016 Aug 31;56(4):205.

3. Wibisono EA, Indramaya DM, Rochmanti M. Retrospective Study: Initial Pharmacotherapy Profile Of New Acne Vulgaris Patients. Jurnal Berkala Epidemiologi. 2020;8(3):236-45.

4. Rahmi KA, Purwono PB, Rochmanti M. Benzalkonium chloride effectiveness as a disinfectant against hospital-associated methicillinresistant Staphylococcus aureus (HA-MRSA). Malaysian Journal of Microbiology. 2019 Apr $1 ; 15(2): 88-94$.

5. Watkins RR, Holubar M, David MZ. Antimicrobial Resistance in Methicillin-Resistant Staphylococcus aureus to Newer Antimicrobial Agents [Internet]. 2019. Available from: http://aac.asm.org/

6. Watkins RR, David MZ, Salata RA. Current concepts on the virulence mechanisms of meticillinresistant Staphylococcus aureus. Journal of Medical Microbiology. 2012 Sep 1;61(9).

7. O’Neill J. Antimicrobial Resistance: Tackling a crisis for the health and wealth of nations. 2014.

8. Zilberberg MD, Nathanson BH, Sulham K, Fan W, Shorr AF. 30-day readmission, antibiotics costs and costs of delay to adequate treatment of Enterobacteriaceae UTI, pneumonia, and sepsis: a retrospective cohort study. Antimicrobial resistance and infection control. 2017;6:124.

9. Wiemken TL, Peyrani P, Ramirez JA. Global changes in the epidemiology of communityacquired pneumonia. Seminars in Respiratory and Critical Care Medicine. 2012;33(3):213-9.

10. Welte T, Köhnlein T. Global and Local Epidemiology of Community-Acquired Pneumonia: The Experience of the CAPNETZ Network. Seminars in Respiratory and Critical Care Medicine. 2009 Apr 18;30(02).

11. Metlay JP, Waterer GW, Long AC, Anzueto A, Brozek J, Crothers K, et al. Diagnosis and treatment of adults with community-acquired pneumonia. American Journal of Respiratory and Critical Care Medicine. 2019 Oct 1;200(7):E45-67.

12. Soepandi PZ, Burhan E, Nawas A, Giriputro S, Isbaniah F, Agustin H, et al. Pneumonia Komunitas, Pedoman Diagnosis dan Penatalaksanaan di Indonesia. 2014.

13. van der Meer JWM, Gyssens IC. Quality of antimicrobial drug prescription in hospital. Clinical Microbiology and Infection. 2001;7(SUPPL. 6):12-5.

14. Raz-Pasteur A, Shasha D, Paul M. Fluoroquinolones or macrolides alone versus combined with $\beta$-lactams for adults with community-acquired pneumonia: Systematic review and meta-analysis. International Journal of Antimicrobial Agents. 2015 Sep;46(3).

15. Garin N, Genné D, Carballo S, Chuard C, Eich G, Hugli $O$, et al. $\beta$-Lactam Monotherapy vs $\beta$-LactamMacrolide Combination Treatment in Moderately Severe Community-Acquired Pneumonia. JAMA Internal Medicine. 2014 Dec 1;174(12).

16. Postma DF, van Werkhoven $\mathrm{CH}$, van Elden LJR, Thijsen SFT, Hoepelman AIM, Kluytmans JAJW, et al. Antibiotic Treatment Strategies for Community-Acquired Pneumonia in Adults. New England Journal of Medicine. 2015 Apr 2;372(14).

17. Cunha BA. The atypical pneumonias: clinical diagnosis and importance. Clinical Microbiology and Infection. 2006;12.

18. McGeer D, Green AK, Low DE. Macrolide Resistance in Bacteremic Pneumococcal Disease: Implications for Patient Management. Clinical Infectious Diseases. 2006 Aug 15;43(4). 
19. Lonks JR, Garau J, Gomez L, Xercavins M, Ochoa de Echagüen A, Gareen IF, et al. Failure of Macrolide Antibiotic Treatment in Patients with Bacteremia Due to Erythromycin-Resistant Streptococcus pneumoniae. Clinical Infectious Diseases. 2002 Sep;35(5).

20. Centers for Disease Control and Prevention. Active Bacterial Core Surveillance (ABCs) Report Emerging Infections Program Network Streptococcus pneumoniae. 2016 [cited 2020 Nov 3]; Available from: https://www.cdc.gov/abcs/ reports-findings/survreports/spneu16.pdf

21. Kalil AC, Metersky ML, Klompas M, Muscedere J, Sweeney DA, Palmer LB, et al. Management of Adults With Hospital-acquired and Ventilatorassociated Pneumonia: 2016 Clinical Practice Guidelines by the Infectious Diseases Society of America and the American Thoracic Society.
Clinical Infectious Diseases. 2016 Sep 1;63(5).

22. Caballero J, Rello J. Combination antibiotic therapy for community-acquired pneumonia. Annals of Intensive Care. 2011 Dec 23;1(1).

23. Leppin AL, Gionfriddo MR, Kessler M, Brito JP, Mair FS, Gallacher K, et al. Preventing 30-Day Hospital Readmissions. JAMA Internal Medicine. 2014 Jul 1;174(7).

24. Jang JG, Ahn JH. Reasons and Risk Factors for Readmission Following Hospitalization for Community-acquired Pneumonia in South Korea. Tuberculosis and Respiratory Diseases. 2020;83(2).

25. de Alba I, Amin A. Pneumonia Readmissions: Risk Factors and Implications. 2014.

26. Henig O, Kaye KS. Bacterial Pneumonia in Older Adults. Infectious Disease Clinics of North America. 2017 Dec;31(4). ing season (40). 